\title{
Moderated Mediation of Ethical Considerations between Individual Values and Values in the Practice of the CPA Profession
}

\author{
Arnold V. Salcedo
}

Holy Angel University, Angeles City, Philippines

\begin{abstract}
CPA Baby Boomers, Generation X, Generation Y or Millennials and the latest addition, Generation Z, possess unique characteristics, workplace values and ethics. This study focused on how workplace values and ethical considerations directly and indirectly affect the values of CPAs. The participants are five hundred forty-one ( $\mathrm{n}=541)$ Baby Boomers, Generation X, Generation Y and Generation Z Filipino professional accountants among four different sectors namely the academe or education, commerce \& industry, government and public practice. A partial least square-structural equation modeling (PLS-SEM) including mediation and moderation analysis were used to determine the direct and indirect effects. Using Schwartz motivational values, the study revealed that there is a positive and significant relationship between self-transcendence (benevolence and universalism) and openness to change (self-direction and stimulation) as workplace values to the values of practicing CPAs. There is a negative but significant relationship between workplace values of conservation (tradition and security) and self-enhancement values (power and achievement) with the CPA values. Also, workplace values significantly affect ethical considerations, while ethical considerations (or strict adherence to CPA's code of ethics) significantly influence the CPA values while in practice. Lastly, the moderation analysis further revealed that workforce generation has moderating effect on the relationship between conservation values and the actual practice values. Ethical considerations have no mediating effect on the significant positive relationship between individual values and values in practice (benevolence and universalism), while workforce generations have moderating effect in the conservation values of CPAs.
\end{abstract}

Keywords: workforce generations; Certified Public Accountant; ethical considerations; workplace values; ethics

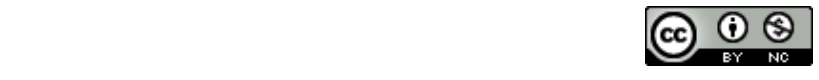

This is an open access article under the CC-BY-NC license

\section{INTRODUCTION}

A lot of studies have focused on the inter-generational differences. There are a lot of challenges that relate to effectively managing multi-generational workforce as diversity is brought in the workplace. Thus, the needs and values must be addressed in order to have high performing organizations (Lieber, 2010). The shift in the dynamics in the workplace coupled with the ethical choices of one generation may be similar or vastly different to the cohorats that came before them (Inciong, 2019). The Baby Boomers, Generation X, Generation Y and the latest addition, Generation $\mathrm{Z}$ may each possess unique characteristics, workplace values and practices distinct from one another.

Interestingly in the Philippines, in Rodriguez-Valdes (2015) gave the big question on how to lead and manage the gap across workforce generations now that various organization's leadership is shifting towards Generation X, Y and the Generation Z. Understanding each generation is critical considering the profiles of related workforce in terms of perspectives, motivations, ethics, and communications styles. The 
differences in workforce generation could also emanate from the values and ethics of professionals working for organizations such as Certified Public Accountants.

Values serve as the foundation, guide and driver of choices and decisions that also explain feelings and emotions. Furthermore, they serve as the point of connection between one's individual beliefs, hopes, fears and expectations with one's surrounding environment. Alignment in personal values with environment at home, work or with the community, may mean a sense of well-being. Otherwise, there will be a sense of disengagement which impedes a person to reach fulfillment or meet its full potential (Hancock, 2018). Thus, values are important and lasting beliefs or ideals which are shared by the members of a culture. They tell what is good or bad, desirable or undesirable which may have major effect on a person's behavior and attitude.

Individual workplace values are the principles that one person believes, including the personal standards and behavior. An individual having the same workplace values aligned with an organization values leads to a harmonious place. Whereas understanding the workplace values may help avoid conflicts and serve as a guide if the organization create the right environment for its employees (Weedmark, 2018). Whether the organization is old or new, these core values must stay intact as it affects how the business may operate and contribute to the long-term success of the organization. Values must flow down from executive level to the business units and put the right values as they are adhered from top to down (Hsing, 2012).

On the other hand, ethics refers to being critical which involves the examination and critiquing of various moral beliefs and practices which is more than just describing one person's behavior (Mac Donald, 2011). Abiding with ethics further improve internal relations and interactions with external stakeholders (Lozano, 2003). It is an accumulation of values and principles which aim to provide answers to questions of what is good or bad as it also give reasons for acting or refraining from acting. With ethics in mind, one's conduct will either be approved or disapproved. It also supports and contradicts something about virtuous or vicious in the conduct or good or evil (Australian Government Law Commission, 2018).

Ethical consideration emanates from two words which are ethics and consideration. Consideration which involves careful thinking over a period of time or to think about a particular fact before deciding or judging something (Cambridge University Press, 2018). For professionals, it is pivotal to apply ethical considerations before making decisions. Based on other definitions, ethical consideration are recommendations based on a certain model of professional responsibility (Merriam-Webster, 2018). It will constitute on what would or would not be ethical behavior by a professional under specified circumstances. Such concepts of ethical consideration are also applicable in the practice of other professions.

In business studies, there are countless opportunities to study the complex relationships among values, ethics and business because values and ethics are believed to be intertwined as they determine one character (Yates, 2018). Thus, there exists the need to consider various perspectives on business values and ethics, which to include the practice of certain profession.

The professional practice of Accountancy requires the mandatory adherence to Code of Ethics for Professional Accountants as a basis for ethical orientation and decision making of Certified Public Accountants (Professional Board of Accountancy, 2019). The code provides fundamental principles to the General Application of the Code, including Standards for Private and Public Practice. Such principles are integrity, objectivity, professional competence and due care, confidentiality and professional behavior.

Baby Boomers are those who were born between 1946-1964 (Chappelow, 2019) facing the retirement age and are described to possess a strong work ethic, independent and self-assured, 
competitive, goal-centric, resourceful, mentally focused and team-oriented (Pappas, 2016). Generation X are those who are born between 1965 to 1981 and is described to be busier, more self-directed, and are approaching the middle of working careers (Kagan, 2019), if not, are at the peak of their careers and espouse a work hard/play hard mentality (Kane, 2019). Millennials or Generation Y are those born between 1982 to 1994 (Iberrola, 2019) and are labeled them as the me-me-me generation (Time Magazine, 2013). And lastly, Generation $\mathrm{Z}$ who are born between 1995 and 2010 are marked by the Internet and was born with awareness of phone and tablet who are known to be multi-taskers, however, with a short attention span (Iberdrola, 2019).

Determining the peculiar characteristics of each workforce based on generation, it is also interesting to know their differences in terms of professional values, ethical considerations and practices in the Accountancy profession. Regardless of the generation, the challenge, therefore, is adopting workplace values and ethical consideration which prompts people to become professionally committed and consider ethical practices in the conduct of their business, which leads to individual and societal transformation (Naidoo 2014). Thus, this research problem aims to determine the moderated mediation of ethical considerations between individual values and values in the actual practice of the CPA profession.

In line with these, this study seeks to address the research gap by closely studying the link between individual values in the workplace values through the mediation of ethical considerations in the practice of the accountancy profession. The mediation of ethical considerations can further moderated by the possible generational differences of Baby Boomers, Generation X or Millennials Generation Y CPAs, and the Generation Z CPAs.

The study also aims to answer the following specific questions:

1. What are the Individual Workplace Values (IWV) of CPAs categorized based on workforce generations?

2. What is the level of ethical considerations (EC) of workforce generations of CPAs.

3. Does Individual Workplace Values (IWV) directly influence the values in the actual practice (VAP) of the Accountancy profession among professional accountants?

4. Does ethical considerations (EC) directly influence the values in the actual practice (VAP) of the accountancy profession among force generations of CPAs?

5. Does Individual Workplace Values (IWV) directly influence the ethical considerations (EC) among workforce generations of CPAs?

6. Does ethical considerations (EC) mediate between Individual Workplace Values (IWV) and the values in the actual practice (VAP) of the Accountancy profession among CPAs?

7. What are the mediating effects of ethical considerations (EC) on the relationship between Individual Workplace Values (IWV) and values in the actual practice (VAP) of the Accountancy profession among CPAs?

8. What are the moderating effects of workforce generations on the relationship between Individual Workplace Values (IWV) and values in the actual practice (VAP) of the Accountancy profession among CPAs? 


\section{LITERATURE REVIEW}

\section{Self- Transcendence, Self-Enhancement, Conservation and Openness to Change Values}

Schwartz (2012) constructed that shows the ten basic values which can be depicted in a table that presents the motivations for each value. The result of findings among eight-two countries (82). This can be used to identify the most important principles within a group of people and related to profession. While Simón et al. (2017) explained Schwartz model as one of the two most important instruments that are being used to assess the human values and reiterated that values is one that changes overtime.

Table 1. Schwartz Values Motivational Type

\begin{tabular}{|c|c|c|c|}
\hline Values Types & Motivational Goal & $\begin{array}{l}\text { Higher Order Values } \\
\text { Type }\end{array}$ & Bipolar Group \\
\hline Universalism & $\begin{array}{l}\text { Understanding, appreciating, } \\
\text { tolerating and protecting the welfare of } \\
\text { people and nature }\end{array}$ & \multirow[b]{2}{*}{ Self-Transcendence } & \multirow[b]{2}{*}{ First } \\
\hline Benevolence & $\begin{array}{l}\text { Preserving and enhancing the } \\
\text { people's welfare with one who is } \\
\text { frequent and personal encounter }\end{array}$ & & \\
\hline Tradition & $\begin{array}{l}\text { Respecting, becoming committed } \\
\text { and accepting with the ideas and } \\
\text { customs }\end{array}$ & \multirow{3}{*}{ Conservation } & \multirow{3}{*}{ Second } \\
\hline Conformity & $\begin{array}{l}\text { Restraining of actions, impulses and } \\
\text { inclination likely to upset or harm } \\
\text { others and go against expectations and } \\
\text { norms }\end{array}$ & & \\
\hline Security & $\begin{array}{l}\text { Maintaining safety, stability and } \\
\text { harmony, relationship with people and } \\
\text { with oneself }\end{array}$ & & \\
\hline Power & $\begin{array}{l}\text { Yielding control or dominance over } \\
\text { other people and resources, while } \\
\text { maintaining status and prestige }\end{array}$ & \multirow[t]{2}{*}{ Self-enhancement } & \multirow[t]{2}{*}{ First } \\
\hline Achievement & $\begin{array}{l}\text { Personal success by demonstrating } \\
\text { competence by meeting standards }\end{array}$ & & \\
\hline Hedonism & $\begin{array}{l}\text { Sense of pleasure and gratification } \\
\text { for oneself }\end{array}$ & Openness to Change & Second \\
\hline
\end{tabular}

Note: This table presents Simon et al (2017) The Portrait Values Questionnaire: a bibliographic and bibliometric review of the instrument

The different motivational values types are presented on Table 1, can be classified into four higherorder values that are further grouped into two opposite dimensions: self-transcendence and selfenhancement the first contrasting group, while conservation and openness to change as the next contrasting group (Simon et al, 2017). 
Self-transcendence values transcendence values involve acknowledging of the importance of having a caring and intimate personal relationship with children. Self-transcendence values help in daily interactions with children and help control negative feelings (Tal, 2014). Self-enhancement includes values which put emphasis on personal achievement and self-interest (e.g., power, achievement, hedonism), contrast to this is self-transcendence which emphasizes on values that promote the welfare of others (e.g., universalism, benevolence, self-direction), thus forming the first bipolar group of values. Conservation values represents values that endorse the preservation and instilling of the status quo (e.g., tradition, conformity, security). Finally, openness to change reflects values that put importance on independent thought and actions that will favor change (Dinh et al, 2012).

\section{Workplace Values}

The five groups of work environments were addressed in Knafo-Noam and Sagiv (2004) which are enterprising, conventional, social, artistic and investigative working environments. An excerpt of the results of the study is shown on Table 2 that presented various occupations and the corresponding values ranked as first, second and third. Certified public accountant as a profession is not included in the list.

Table 2. Summary of Knafo-Noam and Sagiv (2004) Value Profiles in 32 Occupations

\begin{tabular}{|c|c|c|c|c|}
\hline Occupation & Environment & First & Second & Third \\
\hline Laborer & Realistic & Benevolence & Security & Universalism \\
\hline Cleaner & Realistic & Benevolence & Conformity & Universalism \\
\hline Driver & Realistic & Benevolence & Security & Universalism \\
\hline Shopkeeper & Conventional & Benevolence & Security & Universalism \\
\hline Child Care & Social & Benevolence & Universalism & Security \\
\hline Carpenter/Plumber & Realistic & Security & Benevolence & Self-Direction \\
\hline Mechanic & Realistic & Benevolence & Universalism & Security \\
\hline Shop Manager & Enterprising & Benevolence & Security & Universalism \\
\hline Secretary & Conventional & Benevolence & Security & Universalism \\
\hline Security & Realistic & Benevolence & Security & Universalism \\
\hline Janitor & Realistic & Benevolence & Security & Universalism \\
\hline $\begin{array}{l}\text { Geriatric Aide } \\
\text { (Serving the Elderly) }\end{array}$ & Social & Security & Benevolence & Universalism \\
\hline Clerk & Conventional & Benevolence & Universalism & Security \\
\hline Bookkeeper & Conventional & Benevolence & Security & Universalism \\
\hline Technician & Realistic & Benevolence & Universalism & Security \\
\hline Banker & Enterprising & Benevolence & Security & Self-Direction \\
\hline Sales & Enterprising & Benevolence & Security & Self-Direction \\
\hline Electrician & Realistic & Security & Benevolence & Self-Direction \\
\hline $\begin{array}{l}\text { Kindergarten } \\
\text { Teacher }\end{array}$ & Social & Benevolence & Universalism & Security \\
\hline Computer Specialist & Investigative & Benevolence & Security & Universalism \\
\hline Manager & Enterprising & Benevolence & Security & Universalism \\
\hline
\end{tabular}




$\begin{array}{lllll}\text { Social Community/ } & \text { Social } & \text { Benevolence } & \text { Universalism } & \text { Self-Direction } \\ \text { Service/ Manager } & & \text { Benevolence } & \text { Security } & \text { Universalism } \\ \text { Financial Advisor } & \text { Enterprial } & \text { Benevolence } & \text { Self-direction } & \text { Universalism } \\ \text { Engineer } & \text { Investigative } & \text { Benevolence } & \text { Self-direction } & \text { Universalism } \\ \text { Teacher } & \text { Social } & \text { Benevolence } & \text { Self-direction } & \text { Security } \\ \text { Artist } & \text { Artistic } & \text { Benevolence } & \text { Universalism } & \text { Self-Direction } \\ \text { School Principal } & \text { Social } & \text { Benevolence } & \text { Security } & \text { Universalism } \\ \text { Social Worker } & \text { Social } & \text { Benevolence } & \text { Universalism } & \text { Self-Direction } \\ \text { Doctor } & \text { Investigative } & \text { Benevolence } & \text { Universalism } & \text { Self-Direction } \\ \text { Psychologist / } & \text { Social } & \text { Benevolence } & \text { Universalism } & \text { Self-Direction } \\ \text { Consultant } & \text { Investigative } & \text { Benevolence } & \text { Self-direction } & \text { Universalism } \\ \text { Scientist } & & & & \end{array}$

Table 2 was used in the study of Knafo-Noam and Sagiv (2004) in reference to Holland (1996) which concluded that enterprising work environments (e.g. manager and financial advisor) is influenced negatively by universalism values (self-transcendence). Social work (e.g. nurse, teacher and social worker) environments is influenced positively by benevolence and universalism values (self-transcendence) and negatively with power and achievement (self-enhancement). The artistic environment occupations correlated negatively with conformity values (conservation). Investigative environments (e.g. engineer, doctor and scientist) correlated positively with self-direction values (or self-enhancement) and negatively with traditional values (or conservation).

In Eliason, Guse and Gottlieb (2000), family physicians viewed benevolence (helping keep and improve the people's welfare) as the guiding principle most applicable in their lives; which is coupled with a higher level of professional satisfaction. While in Necla (2016) personal values for pre-service teachers in Turkey are self-direction was ranked as the highest, followed by universalism and thirdly security. Additionally, his research indicated a significant relationship between the teacher's personal value orientations with their attitudes in the teaching profession, a different variable in the study.

In Shafer, Morris and Ketchand (2001) personal values have no influence over auditor's perceptions of the moral intensity in facing an ethical dilemma. Moral intensity on the other hand, is influenced by ethical judgments and different behavioral intentions among AICPAs. While in Karacaer, Gohar, Aygün, Mehmet \& Sayin, Cem (2009) personal values have an effect in the ethical decision-making processes of Pakistani and Turkish professional auditors.

Personal values of managers have always been associated with individual decision behavior (Fritzsche and Oz, 2007). In Steenhaut \& Kenhove (2006) there is a causal relationship between personal values and ethical dimension in decision making in which conservation or traditional value-priorities directly influences the judgment on questionable ethical practices, while self-enhancement values indirectly influence the same. In Waldron \& Fisher (2016) a significant difference between the structure of personal values and in ethical judgments between practitioners and students and the effect of life-stage differences. While ethics can analyze through the auditors' commitment to professionalism through two key professional values: public interest and independence enforcement (Barrainkua and Espinaso-Pike, 2017). 


\section{Ethics and Ethical Considerations}

Ethics in Mac Donald (2011), is to reiterate are moral beliefs, practices, norms, values and behaviors that guides standards of behaviour of an individual. They are very important also for businesses since they set the tone on how to conduct the activities, internal relations and interactions with external stakeholders (Lozano, 2003). There are a number of literatures which studied ethics or ethical considerations as a mediator.

Ethics has a mediating effect on the perceived role of managers to corporate social responsibility practices (Godos-Díez, Fernández-Gago, and Martínez-Campillo, 2011). There is also a significant mediating effect of the implicit institutionalization of ethics between the two variables and in order to curb cheating tendencies, there must be a shared value and ethics system, including an open communication in discussing ethical conflicts and dilemmas. Popoola et al. (2017). Ethical climate has a mediating role on the relationship between leadership and team identification in Cheng and Wang (2015). The use use of formal code of ethics between family owned and non-family-owned firm showed that family firms have a lower tendency to present a social responsibility effort than non-family owned firms, and the use of formal code of ethics mediates the relationship between the variables in Cuadrado-Ballesteros, Rodríguez-Ariza, Garcia-Sanchez, and Martinez-Ferrero (2017). Whereas, moral intensity mediates the relationships between the auditors' ethical orientation as well as auditor self-interest threat on the auditors' ethical decision-making in Johari, Mohd-Sahusi \& Chong (2017). Ethical considerations emanate from academic experiences in Alleyne et al. (2013). In Young (2006), self-efficacy has found no relationship with ethical decision making while individuals with high in self-enhancement values such as power and achievement, made less ethical decisions.

Ethical climate in Hassanian and Shayan (2017) acts a significant mediator between the positive relationship of religious orientation and ethical behavior among professional nurses in Iran. Ethical climate in the study refers to the ethical values and behavioral expectations with the intent to focus on the nurse's behavior in educational medical centers which is pivotal in the improvement of the patient conditions. In Proence (2004), ethics orientation the mediating effect have influence on organizational integrity through inculcating values and compliance through employees' code of ethics orientation.

A positive and meaningful relationship between professional ethics as well as commitment and audit quality in the practice of professional accountants in Nasrabadi and Arbabian (2015). A national values system in terms of ethics, has a moderating effect in which ethics from the accountant's perspective minimizes fraud in Nwanyanwu (2018). There is also a significant relationship between professional code of ethics, punitive measures and professional accounting practice in Gberegbe al. (2016). Punitive measures can also be used to enforce compliance to the professional code of ethics in professional accounting practice. It was also found out that accounting ethics has an impact on the practice of accounting profession in Nigeria in Akadakpo \& Enofe (2013)

Moral intensity has significant relationship to moral recognition, moral judgment and moral intention in relation to moral issues in Yang and $\mathrm{Wu}$ (2009). More so, moral judgment partly mediated the relationship between moral recognition and moral intention. Four factors affect which are: presence of ethics code, ethical support by top management, ethical climate and perceptions on success on ethical practices in Ki, Li and Choi (2011). In Ochotorena (2018) the attitudes of external auditors that includes their ethical behavior and challenges as they assess creative accounting. It was found out that creative accounting is not illegal as there are various accounting options and techniques to financial statement preparers. 
Even in tax practice, personal values have an effect on tax culture in Vehovar, Mumel and Hauptman (2018). Ethical work climates of accountants in Venezia, Venezia and Hung (2010) such as the rules or use of codes, efficiency, and instrumentalism dimensions showed no significant difference between Filipinos and Taiwanese; while caring, self-interest, social responsibility, and personal morality dimensions were among those that showed significant.

\section{Multi-generational Workforce}

Donde (2015) described Generation X (those born between 1965 and 1981) developed behaviors of independence, flexibility and adaptability compared to previous generations. While Millennials or Gen $Y$ have a greater sense of empowerment that resulted them to have more from companies. Despite the differences in work values, in Zabel, Biermeier-Hanson, Baltes, Early, and Shepard (2017), however, found no difference on the work ethics of both generations.

In Hayes (2013), multigenerational differences have an implication within the workforce attitudes, perspectives and behaviors exhibited by the five generational groups: Baby Boomers, Generation X, Generation Y or Millennials, and Generation Z). Generational characteristics have an influence on lifelong decision making, from career choices to lifestyle. It was also found that generational cycles determine political composition of the society. Generation $\mathrm{X}$ were found to be reactive while Generation $\mathrm{Y}$ is a civic generation. Generation $Z$ was considered as the most adaptive generation, while Baby Boomers are the me group. There are generational gaps on job satisfaction in Wilson, Squires, Widger, Cranley and Tourange (2008) with Baby Boomers described as more significantly satisfied than Generations X and $Y$ in their profession. It was also found out that there is a need to improve the job satisfaction among younger generations.

There is also a moderating effect of generational differences in terms of the relationship between workplace fun and outcomes in the individual workplace was carefully studied in Lamm (2009). Lu and Gursoy (2013) found moderating effects of generational differences on the impact of satisfaction and turnover intention. The research found out that the generational difference between Baby Boomers and the Millennials have a significant moderating effect on the influence of emotional job exhaustion and job satisfaction and turnover intention, and the relationship between job satisfaction and turnover intention.

\section{HYPOTHESES}

With limited studies relating to the mediating effect of ethical considerations and moderating effects of generational workforce of CPAs on the relationship of variables, this study explores opportunities to address the existing gap on how ideal workplace values influences actual values being applied in practice particularly in the field of accountancy. Thus, this study would like to test the following:

H1a. Self-Transcendence (workplace values) directly influences the values in the practice of CPA profession.

H1b. Conservation (workplace values) directly influences the values in the practice of CPA profession.

H1c. Self-Enhancement (workplace values) directly influences the values in the practice of CPA profession. H1d. Openness to change (workplace values) directly influences the values in the practice of CPA profession.

H2a. Self-transcendence (workplace values) directly influences ethical consideration.

$\mathrm{H} 2 \mathrm{~b}$. Conservation directly (workplace values) influences ethical consideration.

H2c. Self-enhancement (workplace values) directly influences ethical consideration. 
H2d. Openness to change (workplace values) directly influences ethical consideration.

H3. Ethical consideration mediates the direct influence of self-transcendence to the values in the practice of CPA profession.

H4. Ethical consideration mediates the direct influence of conservation to the values in the practice of CPA profession.

H5. Ethical consideration mediates the direct influence of self-enhancement to the values in the practice of CPA profession.

H6. Ethical consideration mediates the direct influence of openness to change to the values in the practice of CPA profession.

H7. Ethical consideration directly influences the values in the practice of the profession.

H8a. Workforce generation has moderating effects on the relationship of self-transcendence values and values in the actual practice of the CPA profession among generation groups of CPAs (Baby Boomers, Generation X, Generation Y and Generation Z).

H8b. Workforce generation has moderating effects on the relationship of conservation values and values in the actual practice of the CPA profession among workforce generation groups of CPAs .

H8c. Workforce generation has moderating effects on the relationship of self-enhancement values and values in the actual practice of the CPA profession among workforce generation groups of CPAs.

H8d. Workforce generation has moderating effects on the relationship of openness to change values and values in the actual practice of the CPA profession among workforce generation groups of CPAs

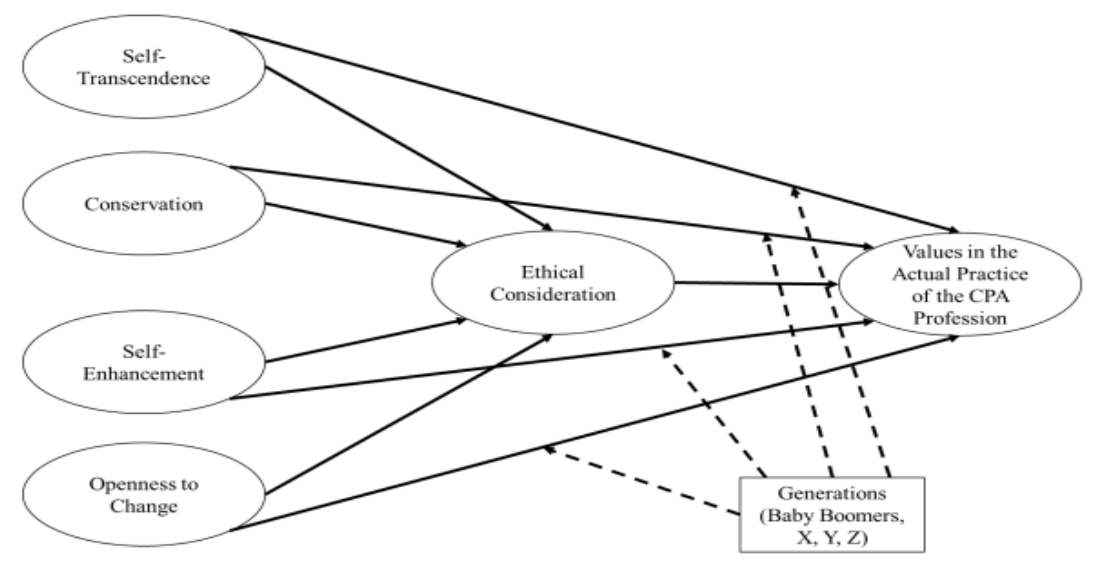

Figure 1. Research Framework

Figure 1 presents the research framework necessary to execute the research. This aim to test how Individual Values in the Workplace influences Ethical Consideration. It also studies how ethical consideration affects the values in the practice of the accountancy profession. The mediating effect of ethical consideration between workplace values and values in the practice of the accountancy profession is also considered. The moderating effect of workforce difference among Baby Boomers, Generation X, Generation Y and Generation Z CPAs will be tackled in the study. 


\section{RESEARCH METHOD}

\section{Research Design}

This study used a cross-sectional descriptive research design since the characteristics of a particular and frequency of the phenomenon on values, workplace values, and ethical considerations of professional accountants are the focus of the study. The units of analysis are individuals, and the point of focus of the research design is the characteristics. Characteristics study the state of being for individuals, thereby as units of analysis (Mendoza, 2012). The research is considered as analytical, since statistics will be used to explain or give substance to a theory and -non-experimental, since the instrument to be used is a survey.

\section{Sample and Setting}

Purposive sampling method was employed while the sample size was determined using the software Warp PLS 6.0 particularly, the Gamma Experimental Method using the inverse square Root method under the Structural Equation Modelling. The inverse square root method uses the inverse square root of the size of the sample in estimating standard error. The gamma-exponential method uses gamma and exponential smoothing function corrections which will be utilized in estimating standard error. The inverse square root and gamma-exponential methods simulate Monte Carlo experiments, and the estimates are the respondents of the study while for Generation Z CPA cohorts who are born 1995 -2010 are the participants of the study.

The sample size of the study comprised of Certified Public Accountants among the four different sectors of the Accountancy profession namely: academe or education, commerce and industry, government and public practice among Certified Public Accountants based in province of Pampanga as of June 2020, were the participants of the study.

\section{Minimum significant path coefficient: .11}

Significant level: 0.05

\section{Power level: .80}
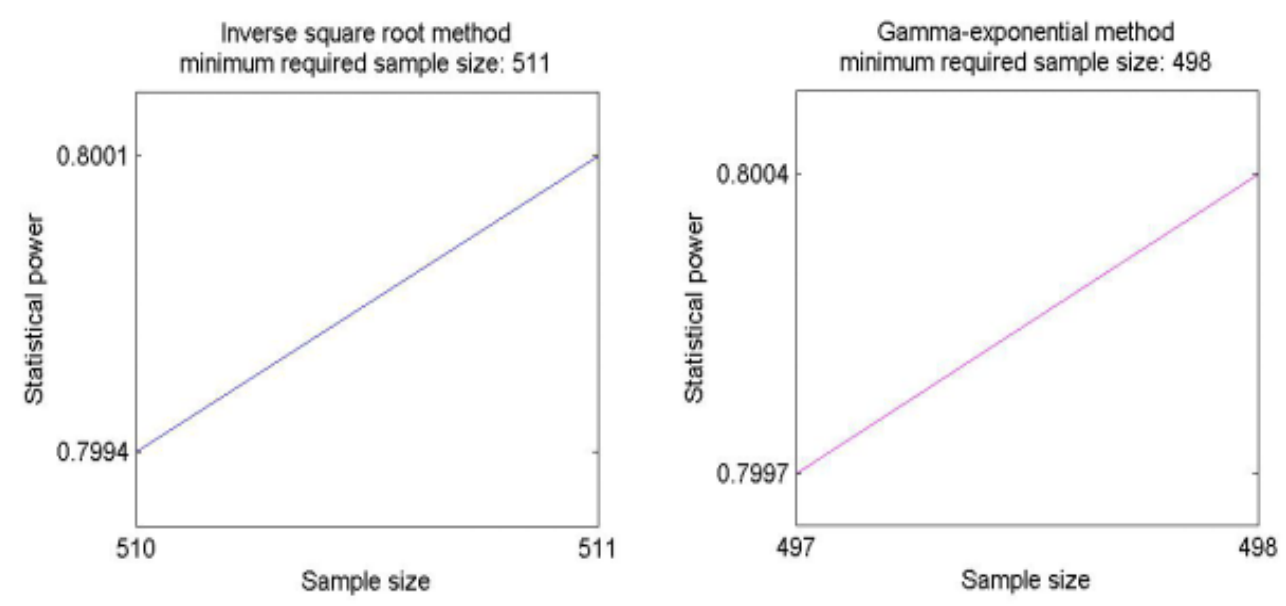

Figure 2. Sample Size Sufficiency Computations using Inverse-Square Root and Gamma Exponential Methods thru PLS-SEM 
Figure 2 was illustrated to check the sufficiency of the sample size using the inverse square root method and gamma-exponential methods. In Kock and Hadaya (2018), one of the most fundamental issues with the use of PLS-SEM is the minimum sample size estimation, which can be achieved by the use of the of the two aforementioned methods. The inverse square root method uses the inverse square root of a sample size for standard error estimation which is a very important step in minimum sample size estimation. The second method is gamma-exponential method that relies on gamma and exponential smoothing function corrections applied to inverse square method (the first method). The Monte Carlo experiments showed that both methods are fairly accurate making the first method more attractive because of its simplicity Any number beyond the range is still acceptable.

With the minimum significant path coefficient 0.11 , significance level of 0.05 and power level of 80 , the results of sample size estimation are 511 for the inverse square root method and 498 for the gammaexponential method. Therefore, the sample size was not less than 498 but can exceed 511 .

Table 3. Demographics

\begin{tabular}{|c|c|c|}
\hline Demographic Characteristics & Frequency & Percent \\
\hline \multicolumn{3}{|l|}{ Generation } \\
\hline Baby Boomer & 13 & 2.4 \\
\hline Gen X & 74 & 13.7 \\
\hline Gen Y & 384 & 71 \\
\hline Gen Z & 70 & 12.9 \\
\hline \multicolumn{3}{|l|}{ Gender } \\
\hline Male & 185 & 34.2 \\
\hline Female & 356 & 65.8 \\
\hline \multicolumn{3}{|l|}{ Form of Business Organization } \\
\hline Single Proprietorship & 32 & 6.1 \\
\hline Partnership & 71 & 13.1 \\
\hline Corporation & 437 & 80.8 \\
\hline \multicolumn{3}{|l|}{ Level of Position } \\
\hline Top Management & 46 & 8.5 \\
\hline Middle Management & 43 & 7.9 \\
\hline Supervisory & 142 & 26.2 \\
\hline Rank and File & 310 & 57.1 \\
\hline Sector (Full-time) & & \\
\hline
\end{tabular}


Academe/Education

Commerce/Industry

Government

Public Practice

Length of experience in the Profession

10 years - below

$11-20$ years

$21-30$ years

31 - above years

Highest Educational Attainment

Bachelor's Degree

Master's Degree

Doctorate Degree
49

94

86

433

11

\section{8}

0

\section{.2}

$\begin{array}{rr}468 & 86.4 \\ 69 & 12.8 \\ 4 & 0.8\end{array}$

\section{Instruments}

The questionnaire had four parts. The first part contained profile categories such as name, age, sex, sector, highest educational attainment, length of work experience age and highest educational attainment. This provided basic information about the respondents. The second part is a questionnaire which is composed of the abridged version of Schwartz's Value Survey which aims to identify the values that is in consonance or opposed principles based on varying degrees that the Professional Accountant or CPA can identify himself or herself. The third part of the questionnaire contains statements that assesses the level of ethical consideration the Certified Professional Accountant which is adapted on the 2018 Revised Code of Ethics for Professional Accountants, particularly under the general application part of the Code. The last part of the survey are statements that relates to the general practice of Professional Accountants (regardless of the sector) and the level of agreeableness to the given statements. All of the instruments will undergo reliability and validity tests.

The instrument used a six-point likert scale preferred by psychometricians. In Thompson (2018), in order to generate a force choice if at any point a neutral is desired, the responses, "slightly agree" and "slightly disagree" can be used. Additionally, an even number of items in the response scale can generate groupings which are easier to understand and discuss. For example, in many organizations these could be groupings of unfavorable, uncertain, and favorable. A perfect example is favorability which is the combination of responses that are either "agree" or "strongly agree."

Data Collection

Through an informed consent, survey questionnaires from recruited participants, were provided. The self-administered survey already provides the results because each respondent had the option to selftally the answers. Secondary sources of information quotes from publications, such sources include comments on, interpretations of, or discussions about the original research conducted abroad. The analysis primary and secondary sources plus the review of survey results would determine the extent of 
relationship between and among workplace values, ethical consideration and the practice of the Professional Accountants.

\section{Data Analysis}

Partial least square structural equation modelling (PLS-SEM) using Warp PLS 6.0 was used to measure the variables of structural model. PLS-SEM provides structural model which displays the relationships through paths between or among constructs. The measurement models also display the various relationships between constructs and variables.

As the present study also evaluates the mediating effects of ethical consideration, a mediation-based research will be used. In Hair, Sarstedt, Hopkins and Kuppelwieser (2014), a mediation model measures how mediator/s, to some extent, absorb the effect of the exogenous construct on an endogenous variable in PLS-SEM. As to the assessment of the respondent's on the level of importance of their values as lifeguiding principle, the respondents were asked to rank the values that correspond to the given statement on the questionnaire. For purposes of ranking and analysis, a numerical value was assigned to the dummy values that represents the ordinal ranking presented.

\section{Ethical Considerations}

The consent of the participants were obtained and assurance not to reveal personal information based on the results will be explained. Permission from the author to use the Workplace Values Questionnaire and adapted survey is also requested. Results of the research are used for academic and knowledge preservation purposes only. References of the authors are acknowledged by citing them as references of the study.

\section{FINDINGS AND DISCUSSION}

\section{Findings on Model Fit and Quality}

What is unique about PLS-SEM, particularly with the use of PLS, is that it provides users with a number of model-wide fit indices average path coefficient (APC), average R-squared (ARS), average adjusted R-squared, average variance inflation factor (AFVIF), average full collinearity variance inflation factor (AFVIF) and Tenenhaus goodness of fit (GoF) according to Kock (2010). The p-values of APC, ARS and AARS must be equal or lower than 0.05 (Kock, 2018), in order for the model to become acceptable. Having the values of 0.169 for APC, 0.197 for ARS and 0.191 for AARS as shown on Table 4, which reflects an equivalent $p$ values which are less than 0.05 , the acceptance is within the acceptable range.

According to Kock (2018), the corresponding AVIF and AFVIF must be equal to or lower than 3.3 in order for the model to become acceptable. Tenenhaus Good of Fit, which serves a measure of the explanatory power of the model, the following thresholds or ranges must be observed: small if equal or more than 0.1, medium if equal or greater than 0.25 and large if equal or larger than 0.36 (Kock, 2018; Wetzels et al. 2009; Tenenhaus et al, 2005). The Tenenhaus Good of Fit is also within the acceptable range particularly medium as presented on Table 8.

Table 2 presents the analysis results of the five emotional intelligence dimensions. Four dimensions, i.e. emotional recognition and expression (ERE), emotions direct cognition (EDC), emotional management (EM), and emotional control (EC), had a significant relationship with organisational performance. Using the $t$ values as a guide, we found that ERE and EDC had a significant influence on the employees. This indicates that workers with higher emotional intelligence tend to be better at recognising and expressing their emotions. Also, they have better skills in decision making, which is an important responsibility of the executives. 
Table 4. Model Fit and Quality Indices

\begin{tabular}{ll}
\hline Model Fit and Quality Indices & Coefficients \\
\hline APC & $0.169, \mathrm{P}<0.001$ \\
ARS & $0.197, \mathrm{P}<0.001$ \\
AARS & $0.191, \mathrm{P}<0.001$ \\
AVIF & 1.139 , acceptable if $<=5$, ideally $<=3.3$ \\
AFVIF & 1.213 , acceptable if $<=5$, ideally $<=3.3$ \\
Tenenhaus GoF & 0.322, small $>=0.1$, medium $>=0.25$, large $>=0.36$ \\
\hline
\end{tabular}

\section{Findings on the Validity and Reliability Measurements}

To present the robustness when it comes to the results of the study, the assessment of reliability and validity of the variables used is imperative. Reliability is the extent that whatever the instrument measures, it measures consistently (Siegle, 2013). According to Huck (2007), testing for reliability is very important because refers to the consistency across the parts of a measuring instrument. The scale is said to have a high internal consistency reliability if the items of a scale in the instrument "hang together" and measure the same construct (Huck, 2007, Robinson, 2009). There are two measures of reliability - the Cronbach's Alpha and composite reliability (Roldan and Sanchez-Franco, 2012; Kock, 2018). Comparing the two measures of reliability, the composite reliability generally, is a more acceptable measure that is available (Dillon \& Gold Stein, 1984; Peterson \& Yeolib, 2013).

Moreover, both Cronbach Alpha and composite reliability coefficients must be higher equal or greater than 0.7 (Fornell and Larcker, 1981; Nunally, 1978; Nunnally and Bernstein, 1994). Table 9 presented that all constructs (after item reduction, where 12 statement items were removed out of the 46 statements) reflects high reliability where composite reliability is greater than 0.7 (even if the some of the Cronbach Alpha is less than 0.7). Again, it is to be noted that the use of composite reliability is more acceptable compared to Cronbach Alpha.

In terms of construct validity, both convergent and discriminant validity checks were executed. According to Kock (2018), convergent validity measures the quality of a measurement instrument, that itself contains a set of questions. A good convergent validity is achieved if the question, statements or other measures associated with each latent variable are clearly understood by the respondents from which they are intended by the designer or author of the research. To say that a measurement model has an acceptable construct validity, the p-values of each item must be equal to or lower than 0.05 and the loadings must be equal or greater than 0.5 (Hair et al., 1987; 2009; Kock, 2018). Item loading refers to the correlation between the construct and the item (Kock, 2018). Table 5 again presents that the factor loadings for each item. All constructs are statistically significant at $0.001(\mathrm{p}<.001)$ and the item loadings are greater than 0.5 .

The assessment of the convergent validity includes the measurement of the amount of the variance of each variable from its items in relation to the amount due to measurement error or simply the average variance extracted or (AVE). This is a measure that is being used to assess convergent validity which is the average of the variance amount in indicator variables that a construct is able to explain (IGI Global, 2019). According to Fornell and Larcker (1981), the AVE must be equal or greater than 0.5, but for instances where the AVE is less than 0.5 (Table 5, values in the actual practice of the profession construct) the composite reliability must be higher than 0.6 in order to for the construct validity to be adequate. Therefore, the coefficients of AVE were able to satisfy the acceptable validity requirements. 
Journal of Governance Risk Management Compliance and Sustainability (JGRCS), Vol. 1 (1), 26-49 Moderated Mediation of Ethical Considerations between Individual Values and Values in the Practice of the CPA Profession Arnold V. Salcedo

Table 9. Factor Loading, Average Variance Extracted, and Reliability Measures (after Item Reduction)

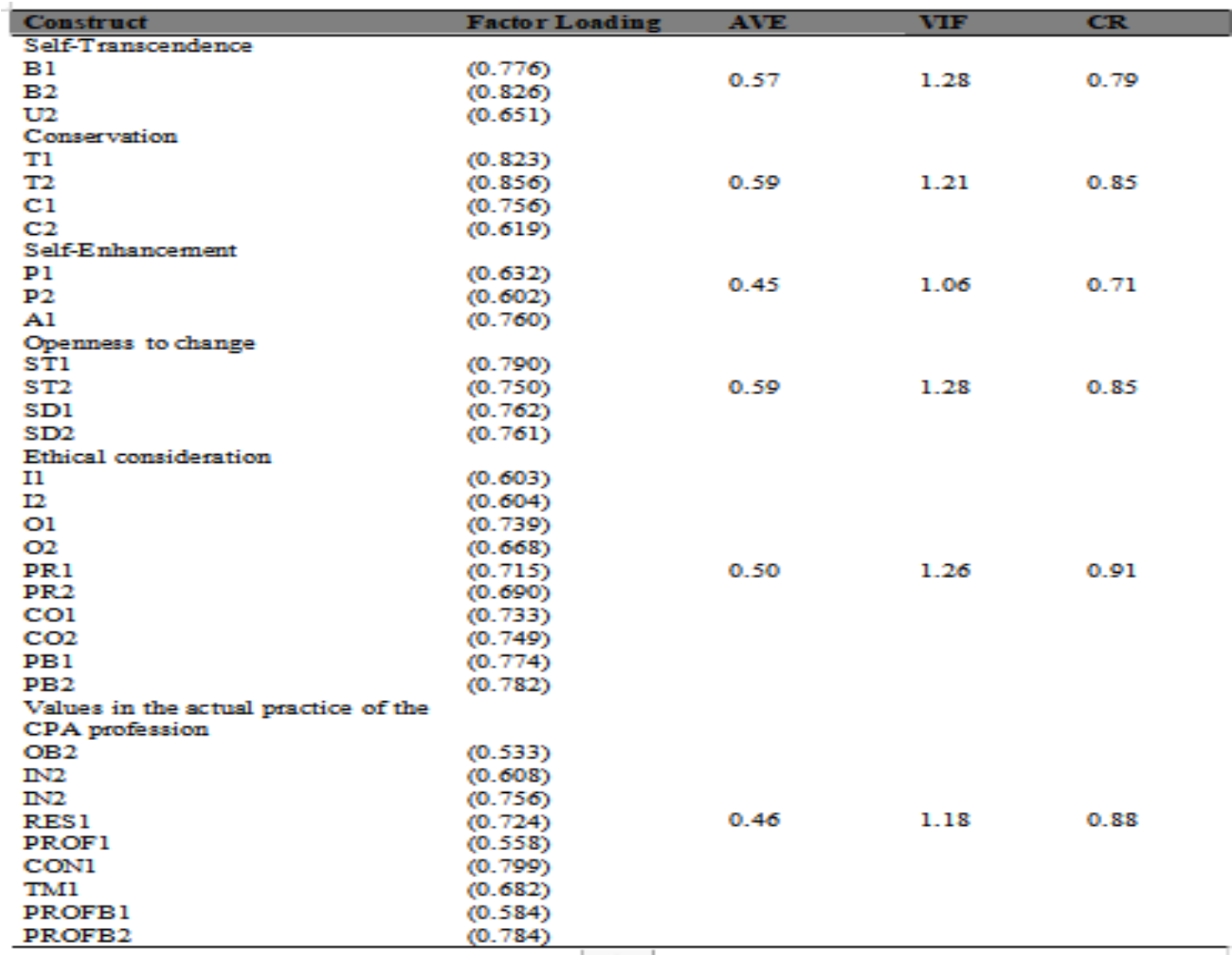

Note: All item indicators are significant at $0.001(\mathrm{p}<.001)$. AVE = average variance extracted; VIF = variance inflation factor; $\mathrm{CR}=$ composite reliability; VIF - variance inflation factor

Table 6 shows the correlations among variables which also include the square roots of the AVE coefficients, this time to measure the discriminant validity of the instrument. According to Kock (2018), discriminant validity is a measure whether the question statements (or other measures) associated with each latent variable are not construed against or confused by the other respondents who are answering the questionnaire with the question-statements associated with the other latent variables. In short, it checks whether the statements that is related to one variable, for example, are not confusing with the statements that are related to other variables. Table 9 shows the square root of the AVE, which should be greater than any of the correlations involving the variables (Fornell and Larcker, 1981). Based on the results on Table 9, the results indicate that the measures used in the instrument has discriminant validity.

Table 6. Square Roots of AVE Coefficients and Correlation Coefficients

\begin{tabular}{lcccccc}
\hline & SELFTRAN & CONSERV & ENHANCE & OPENNESS & ETHICALC & VALUES \\
\hline SELFTRAN & $(0.755)$ & & & & & \\
CONSERV & 0.255 & $(0.769)$ & & & \\
ENHANCE & 0.070 & 0.148 & $(0.668)$ & & \\
OPENNESS & 0.362 & 0.137 & 0.154 & $(0.766)$ & \\
\hline
\end{tabular}




\begin{tabular}{lllllll}
\hline ETHICALC & 0.329 & 0.062 & 0.013 & 0.366 & $(0.708)$ & \\
VALUES & 0.054 & -0.302 & -0.136 & 0.081 & 0.197 & $(0.677)$ \\
\hline
\end{tabular}

Note: Diagonal elements are the square root of AVE of constructs while the off-diagonal elements are the correlation between constructs. SELFTRAN - Self-Transcendence; CONSERV Conservation; ENHANCE - Self-Enhancement; OPENNESS - Openness to change; ETHICALC Ethical consideration; VALUES - Values in the actual practice of the CPA profession.

\section{Findings on Linear Model Hypotheses Explanations}

Figure 4 reflects the path model and the corresponding path coefficients. The results are presented in Figure 4 revealed that self-transcendence values $(\beta=0.12, p<.01)$ and openness to change values $(\beta=0.11, p<.01)$ are significantly and positively related with the values in the actual practice of the CPA profession. While conservation $(\beta=-.037, p<.01)$ and self-enhancement values $(\beta=-0.17, p<.01)$ are significantly and negatively related with the values in the actual practice of the CPA profession.

Moreover, self-transcendence values $(\beta=0.24, p<.01)$ and openness to change values $(\beta=0.28, p$ $<.01)$ are significantly and positively related with the ethical considerations. Conservation values $(\beta=0.03$, $\mathrm{p}=0.31$ ) are positively and non-significantly related with ethical considerations, and on the other hand, self-enhancement values $(\beta=-0.04, p=.18)$ are negatively and non-significantly related with ethical considerations.

In terms of ethical considerations and the values in the actual practice of the CPA profession, the results showed the they are positively and significantly related $(\beta=0.17, \mathrm{p}<.01)$.

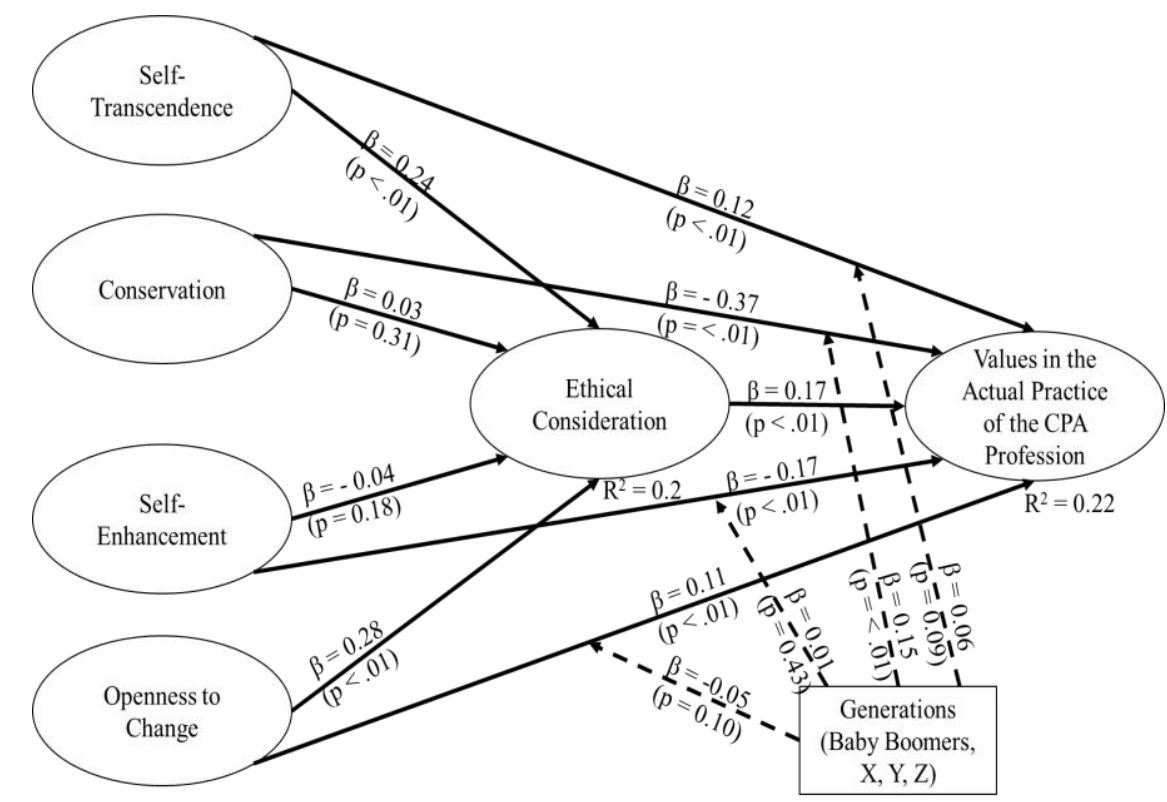

Figure 4. The PLS path model with path coefficients

\section{Direct and Indirect (Mediating) Effects}

Findings of the study have shown that workplace values particularly self-transcendence values $(\beta=0.118, p=0.003)$ and openness to change values $(\beta=0.110, p=0.005)$ positively affects values in the actual practice of the CPA the profession. The positive beta coefficients indicate that self-transcendence values (Cohen's $\mathrm{f} 2=0.009$ ) and openness to change values (Cohen's $\mathrm{f} 2=0.015$ ) augments values in the 
actual practice of the CPA profession with small and medium effect sizes respectively. Therefore, hypotheses H1a and H1d are accepted.

Moreover, conservation values $(\beta=-0.373, p<0.001)$ and self-enhancement values $(\beta=-0.169, p<$ 0.001 ) negatively affects values in the actual practice of the CPA profession. The negative beta coefficients show that conservation values (Cohen's $f 2=0.123$ ) and self-enhancement values (Cohen's $f 2=0.043$ ) diminish values in the actual practice of the CPA profession with small effect sizes. Thus, hypotheses $\mathrm{H} 1 \mathrm{~b}$ and $\mathrm{H} 1 \mathrm{c}$ are also accepted. In terms of the high-order values type's relationship with ethical considerations, both self-transcendence values $(\beta=0.243, p<0.001)$ and openness to change $(\beta=0.284, p<0.001)$ values positively affects ethical consideration. An increase in the CPAs self-transcendence values (Cohen's $\mathrm{f} 2=$ 0.084 ) and openness to change values (Cohen's $\mathrm{f} 2=0.105$ ) positively affect a CPAs ethical consideration. In this case, hypotheses $\mathrm{H} 2 \mathrm{a}$ and $\mathrm{H} 2 \mathrm{~d}$ are accepted. On the other hand, both conservation values $(\beta=0.034$, $\mathrm{p}=0.215)$ and self-enhancement values $(\beta=-0.039, \mathrm{p}=0.182)$ are not significantly related to ethical considerations. Therefore, $\mathrm{H} 2 \mathrm{~b}$ and $\mathrm{H} 2 \mathrm{c}$ hypotheses are rejected. Finally, ethical considerations $(\beta=0.69$, $\mathrm{p}<0.001$ ) significantly affects the values of the CPAs in the actual practice of the profession. As CPAs follow ethics, the values in the actual practice are also enhanced. Thus, hypothesis 7 is also accepted.

Table 7 also shows the indirect effects of the mediation model. The findings of the study revealed that ethical considerations does not mediate the relationship between self-transcendence values $(\beta=$ $0.041, p=0.088)$, conservation values $(\beta=0.006, p=0.426)$ self-enhancement values $(\beta=-0.007, p=$ $0.002)$ and openness to change $(\beta=0.048, p=.028, p=0.057)$ with values in the actual practice of the CPA profession. Therefore, hypotheses $\mathrm{H} 3, \mathrm{H} 4, \mathrm{H} 5$ and $\mathrm{H} 6$ are rejected.

Table 7. Direct and Indirect (Moderating) Effects of the PLS Path Model

\begin{tabular}{|c|c|c|c|c|c|}
\hline Hypothesis & $\beta$ & SE & $\begin{array}{l}\text { p-valu } \\
\text { e }\end{array}$ & $\mathrm{f}^{2}$ & Decision \\
\hline \multicolumn{6}{|l|}{ Direct Effects } \\
\hline H1a. Self-Transcendence $\rightarrow$ CPA Values & 0.118 & 0.042 & 0.003 & 0.009 & Accept \\
\hline H1b. Conservation $\rightarrow$ CPA Values & -0.373 & 0.041 & $<0.001$ & 0.123 & Accept \\
\hline H1c. Self-Enhancement $\rightarrow$ CPA Values & -0.169 & 0.042 & $<0.001$ & 0.043 & Accept \\
\hline H1d. Openness to Change $\rightarrow$ CPA Values & 0.110 & 0.042 & 0.005 & 0.015 & Accept \\
\hline $\begin{array}{l}\text { H2a. Self-Transcendence } \rightarrow \text { Ethical } \\
\text { Consideration }\end{array}$ & 0.243 & 0.042 & $<0.001$ & 0.084 & Accept \\
\hline $\begin{array}{l}\text { H2b. Conservation } \rightarrow \text { Ethical } \\
\text { Consideration }\end{array}$ & 0.034 & 0.043 & 0.215 & 0.004 & Reject \\
\hline $\begin{array}{l}\text { H2c. Self-Enhancement } \rightarrow \text { Ethical } \\
\text { Consideration }\end{array}$ & -0.039 & 0.043 & 0.182 & 0.005 & Reject \\
\hline $\begin{array}{l}\text { H2d. Openness to Change } \rightarrow \text { Ethical } \\
\text { Consideration }\end{array}$ & 0.284 & 0.042 & $<0.001$ & 0.105 & Accept \\
\hline $\begin{array}{l}\text { H7. Ethical Consideration } \rightarrow \text { CPA Values } \\
\text { Indirect Effects }\end{array}$ & 0.169 & 0.042 & $<0.001$ & 0.033 & Accept \\
\hline $\begin{array}{l}\text { H3. Self-Transcendence } \rightarrow \text { Ethical } \\
\text { Consideration } \rightarrow \text { CPA Values }\end{array}$ & 0.041 & 0.030 & 0.088 & 0.003 & Reject \\
\hline $\begin{array}{l}\text { H4. Conservation } \rightarrow \text { Ethical Consideration } \\
\rightarrow \text { CPA }\end{array}$ & 0.006 & 0.030 & 0.426 & 0.002 & Reject \\
\hline $\begin{array}{l}\text { H5. Self-Enhancement } \rightarrow \text { Ethical } \\
\text { Consideration } \rightarrow \text { CPA Values }\end{array}$ & -0.007 & 0.030 & 0.414 & 0.002 & Reject \\
\hline $\begin{array}{l}\text { H6. Openness to Change } \rightarrow \text { Ethical } \\
\text { Consideration } \rightarrow \text { CPA Values }\end{array}$ & 0.048 & 0.30 & 0.057 & 0.006 & Reject \\
\hline
\end{tabular}


Table 8 presents the Moderating Effect on the Relationship of Workplace Values and Values in the Actual Practice of the CPA Profession among Generation BB, X, Y and Z. Using constrained latent growth method, analysis of the data revealed that workforce generations do not moderate the relationship between workplace values such as self-transcendence, self-enhancement and openness to change values with values in the actual practice of the CPA profession except conservation values. The study showed there is a significant difference on the relationship conservation workplace values $(\beta=0.153 p<.001$ and values in the actual practice of the CPAs profession. Therefore, H8b is accepted while H8a, H8c and H8d hypotheses are rejected.

Table 8. Moderating Effect on the Relationship of Workplace Values and Values in the Actual Practice of the CPA Profession among Generation BB, X, Y and Z

\begin{tabular}{lllcll}
\hline $\begin{array}{l}\text { Moderating Effects of } \\
\text { Generations }(\mathrm{BB}, \mathrm{X}, \mathrm{Y}, \mathrm{Z})\end{array}$ & $\beta$ & $\mathrm{SE}$ & $\begin{array}{c}\mathrm{p}- \\
\text { value }\end{array}$ & $\mathrm{f} 2$ & Decision \\
\hline H8a. Self-Transcendence $\rightarrow$ CPA & 0.058 & 0.043 & 0.088 & 0.006 & Reject \\
Values & & & & & \\
$\quad$ H8b. Conservation $\rightarrow$ CPA Values & 0.153 & 0.042 & $<0.001$ & 0.018 & $\begin{array}{c}\text { Accept } \\
\text { H8c. Self-Enhancement } \rightarrow \text { CPA }\end{array}$ \\
$\begin{array}{l}\text { Values } \\
\text { H8d. Openness to Change } \rightarrow \text { CPA }\end{array}$ & -0.007 & 0.043 & 0.431 & 0.001 & Reject \\
Values
\end{tabular}

Note: $\mathrm{f} 2$ is the Cohen's (1988) effect size: $0.02=$ small, $0.15=$ medium, $0.35=$ large; $\mathrm{SE}=$ standard error; $\beta=$ standardized path coefficient

\section{Discussion}

Values coupled with ethics are important research topics of various scholars across different disciplines, such as social work and practice (Banks, 2012; Reamer, 2013), change management (By and Oswick, 2012), library information science (Koehler, 2003), psychotherapy and counselling (Barnes, 2001), healthcare (Fulford, 2002) and many others. However, values and ethics have not much been thoroughly discussed in researches in the practice of the accountancy profession, where most of the studies focus on values, ethics and practice separately; if not on the impact of ethics to the practice of accountancy (Akadakpo and Enofe, 2013).

The present study confirmed that self-transcendence values are significantly and positively related with the values in the actual practice of the CPA profession. The results also support the studies of KnafoNoam and Sagiv (2004), where the profession accountancy maybe classified under both social and investigative environments, where social work environments (e.g. nurse, teacher and social worker) is influenced positively by benevolence and universalism values (self-transcendence) and negatively with power and achievement (self-enhancement); and investigative environments (e.g. engineer, doctor and scientist) correlated positively with self-direction values (or self-enhancement) and negatively with traditional values (or conservation). Accounting is a social science because it is concerned how technical matters such as accounting accounting principles and reports affect people and its relations; its input and output are human nature (Lowe and Puxty, 1990).

Self-transcendence values (benevolence and universalism) and openness to change (stimulation and self-direction) are principal values that drives professional accountants to manifest values in the practice of their profession. Benevolence motivational values is the protection of the organizational interest while universalism is to safeguard the public interest (Rasouli et al, 2015), contributes positively 
to values in the actual practice of the profession. Meanwhile for stimulation and self-direction, the motivational values counterpart for openness to change, are achieved through the exercise and unimpaired independent professional judgment of a CPA (Rasouli et al, 2015); thus, are essential in causing values to become apparent while in the CPAs practice.

However, self-enhancement and conservation values are significantly and negatively related with the values in the actual practice of the profession. Workplace values that focus too much on power in order to maintain social status, prestige, or dominance over people and authority (Potts, 2015), and the values of achievement that drives one to be ambitious and successful (Rasouli et al 2015) may inhibit values during the practice of accountancy profession. Conservation values (tradition and conformity), are likewise negatively related with practice values. Tradition promotes sticking to traditional or old methods and the use of customs learned, while conformity promotes obedience and subordination to the organization's interest (Potts, 2015).

Therefore, possessing workplace values that put emphasis on the continuous update and professional development with the changes in the conventions and standards in the accountancy profession (openness to change), while protecting and considering other stakeholder's interest in the practice of the profession (self-transcendence) contributes positively to the values of a CPA while practice. These values are opposing to the bipolar counter parts which are self-enhancement and conservation that suggests placing self-interest above the public's interest and by becoming attached to old conventions in the practice of the profession (Simon et al, 2017).

The study also reasserts both self-transcendence and openness to change values are significantly and positively related with ethical considerations. Furthermore, it affirms that conservation and selfenhancement values have no significant relationship with ethical considerations. Moreover, the aforementioned results support and negate the studies of

According to Fritzsche and $\mathrm{Oz}$ (2007) there are altruistic or self-less or self-transcendence values (e.g., universalism, benevolence, self-direction) have a positive contribution to ethical decision making, and self-enhancement values have a significant negative contribution (e.g., power, achievement, hedonism) to ethical decision making.

This study also validates that ethical consideration is significantly and positively related with the values in the actual practice of the CPA profession which approximates the studies of Nasrabadi and Arbabian (2015), Akadakpo \& Enofe (2013) and Ki, Li and Choi (2011). Being guided with the five fundamental principles of the code of ethics for professional CPAs - consists of integrity, objectivity, professional competence and due care,confidentiality and professional behavior, positively enhances the values in the actual practice of the CPA profession.

The mediation analysis also revealed that ethical considerations do not mediate the relationship between individual workplace values and the values in the CPA practice of the profession. Lastly, the study also provided an analysis on the difference on the workplace values and CPA values between the workforce generations (Generation Baby Boomers, X, Y and Z) through moderation analysis. The analysis showed that there is a significant difference on the relationship between conservation workplace values with the CPA values compared other values such as self-transcendence, self-enhancement and openness to change values based on the workforce generation. This means that Generation senior CPAs may have ranked and put higher emphasis on conservation values (tradition and conformity) compared with their younger counterparts, thus affecting the relationship. 


\section{CONCLUSION \& FURTHER RESEARCH}

\section{Conclusion and Recommendations}

As a conclusion, ethical considerations have no mediating effect on the significant positive relationship between individual values and values in practice, while workforce generations have moderating effect in the conservation values of CPAs. Ethical considerations and values in the actual practice of the CPA profession are positively influenced by individual workplace values such as openness to change and self-transcendence. Organizations and firms, therefore, must support professional accountants in the pursuit of improving one's self-direction which focuses on independent thinking and acting. Companies must ensure that these professionals are updated with the latest accounting and ethical standards and be constantly guided with trainings, seminars, fora, conventions and conferences. This will allow them to become empowered and draw confidence in the conduct of their profession. CPAs must also be reminded of the crucial role their role as they protect the public's interest (in contrast with the selfish interest of a person, group or firm) where the welfare of the general public is at stake (WebFinanceInc., 2019).

Since ethical considerations enhances CPA values while in practice, the Professional Board of Accountancy must promulgate the mandatory inclusion of ethical training standards as part of the continuous professional development among CPAs. This way, ethical practices can be inculcated among generation $\mathrm{X}$ and $\mathrm{Y}$ CPAs most especially those in public practice and government sectors. The recital of the abridged version of the Code of Professional Ethics, must not be held during Philippine Institute of Certified Public Accountants gatherings, but should include local and sectoral activities of the profession.

Aside from professional accountants, the present study can benefit organizations, businesses and firms during values development process, which begins by identifying the organization's important workplace values as it relates to professionals such as accountants and the mediating effects of other factors. Heathfield (2018) suggested three step process which involved: identifying the values that exists in the workplace, deciding if it is the right values in the workplace and changing the behaviors and actions relative to the values demonstrated when necessary.

The management of these organizations, therefore, must start taking a hard look on the values of the organizational workforce and ethical mechanisms both for workforce generations X, Y and the newly entered generation Z, who will, in a decade's time or soon dominate in number and in seniority, occupy much of the leadership positions. These espoused or core values and code of ethics must be clearly communicated in an easier manner.

\section{Implications to the Profession and Future Research Directions}

Every individual has a unique workplace values that could set the the tone for an organization or firm's culture (Manktelow, 2019). A professional accountant or CPA is also moulded to become ethical as one is mandated to strictly adehere to the Code of Professional Ethics (Professional Board of Accountancy, 2016). According to Tan-Torres (2016), the violation of the code may subject an erring CPA into reprimand, suspension of the professional license, imposition of fines and penalties, license revocation and requirement for the submission or resubmission of a corrected or valid certificate to change defective Certificate due to the sanctions imposed on the violating CPA.

Hence being compliant with the regulatory requirements of the Board of Accountancy, must not only be the motivation for CPAs to be aware of the caveats in the profession, but also must include the recognition of essential workplace values. As suggested in this study, these values are openness to change and self-transcendence values that emphasize on self-direction which requires independent thinking, 
creativity and self-expression from the professional accountant. In addition, the consideration of not only the organization's or client's interest but the public interest, as a whole. However, these values only serve as a guide and the final decision to act and behave accordingly, still lies with the professional CPA.

Now that ethics is relevant in the practice of the profession based on this study, Brennan (2016) identified another major challenge for professional accounting regulatory bodies which is the enforcement of ethical standards, thus enforcement mechanisms are very imperative since professional codes are selfenforced. This is the case in the Philippines, no single notorious case of an erring CPA led to the decision of revoking one's license by the regulatory board.

Other researchers may help improve this study by including other future workforce generations such as Alpha Generation. Furthermore, it can be improved by including in the study the mediating effects of other variables, such as good governance and earnings management. Consistent results in terms of workplace values were also shown among CPAs working for foreign companies where future studies could determine the extent of difference between CPAs working for a local companies and CPAs serving foreign employers.

\section{REFERENCES}

Akadakpo, B. A., \& Enofe, A. O. (2013). Impact of accounting ethics on the practice of accounting profession in Nigeria. Journal of business and management, 12(1), 45-51. . Nigeria. IOSR Journal of Business and Management; Retrieved from: http://www.iosrjournals.org/iosr-jbm/papers/Vol12issue1/G01214551.pdf

Alleyne, P. \& Cadogan-McClean, C. \& Harper, A. (2013). Examining Personal Values and Ethical Behaviour Perceptions between Accounting and Non-accounting Students in the Caribbean. The Accounting Educators' Journal. 23. https://www.researchgate.net/publication/260506903_Examining_Personal_Values_and_Ethical_Behav iour_Perceptions_between_Accounting_and_Non-accounting_Students_in_the_Caribbean

Australian Government Law Commission (2018). Australian Government;Essentially Yours: The Protection of Human Genetic Information in Australia (ALRC Report 96). Ethical Considerations.

Barrainkua, I. and Espinaso-Pike M. (2017). “The influence of auditors' professionalism on ethical judgment: Differences among practitioners and postgraduate students

Cambridge University Press (2018). Cambridge Dictionary https://dictionary.cambridge.org/dictionary/english/consideration

Chappelow, Jim (2019). Investopedia. What is a Baby Boomer? https://www.investopedia.com/terms/b/baby_boomer.asp

Cheng, M. Y., \& Wang, L. (2015). The mediating effect of ethical climate on the relationship between paternalistic leadership and team identification: A team-level analysis in the Chinese context. Journal of business ethics, 129(3), 639-654.https://doi.org/10.1007/s10551-014-2189-5

Cuadrado-Ballesteros, B., Rodríguez-Ariza, L., Garcia-Sanchez, I. M., \& Martinez-Ferrero, J. (2017). The mediating effect of ethical codes on the link between family firms and their social performance. Long Range Planning, 50(6), 756-765. Retrieved from: https://doi.org/10.1016/j.lrp.2016.11.007.

Dinh, J. E., Lord, R. G., Hall, R. J., Hannah, S. T., Leavitt, K., Shondrick, S. J., \& Usher Perez, A. L. (2012). Implicit and explicit values as a predictor of ethical decision-making and ethical behavior. In Proceedings of the New Frontiers in Management and Organizational Cognition Conference. National University of Ireland Maynooth. http://eprints.maynoothuniversity.ie/4052/1/JD_Implicit_values.pdf 
Donde, G. (2015). Management Issues at the Heart of the Changing Workplace: Ethics across generations. Retrieved from: https://www.management

issues.com/news/7081/ethics-across-the-generations/

Fritzsche, D. \& E. Oz, (2007). Personal values' influence on the ethical dimension of decision making._Journal of Business Ethics_ 75 (4):335 - 343.

Gberegbe, F. E., Idornigie, G. A., \& Nkanbia, D. L. O. (2016). Does Professional code of ethics influence professional accounting practice in Rivers state, Nigeria. Journal of Research in Business and Management, 4(1), 14-21. Retrieved from: http://www.questjournals.org/jrbm/papers/vol4-issue1/C411421.pdf

Hair, J.F., Sarstedt, M., Hopkins, L. and G. Kuppelwieser, V. (2014), "Partial least squares structural equation modeling (PLS-SEM) an emerging tool in business research", European Business Review, Vol. 26 No. 2, pp. 106-121, available at: https://doi.org/10.1108/EBR-10-2013-0128

Hancock, J. (2018). The Value of Values - A Manager's Guide. https://www.alchemyassistant.com/topics/6wFfEjLDqtjhTdSM.html.

Hassanian, Z. M., \& Shayan, A. (2017). The mediating effect of ethical climate on religious orientation and ethical behavior. Nursing ethics, 0969733017738133.. https://doi.org/10.1177/0969733017738133

Hayes, B. R. (2013). The implications of multigenerational differences within the workforce. Retrieved from: https://opensiuc.lib.siu.edu/cgi/viewcontent.cgi?referer- https://www.google.com

Holland, John L. (1996). John Holland's Theory Of Career Choice - Theories Every Careers Adviser Should Know.https://runninginaforest.wordpress.com/2015/01/14/john-hollands-theory-of-careerchoice-theories-every-careers-adviser-should-know/

Hsing, Victor (2012). Importance of Values and Attitudes in the Workplace. National Academey of CivilService.

http://www.nacs.gov.tw/NcsiWebFileDocuments/5ffc23aa91844502bfded47df08d57e9.pdf

Inciong, E. (2019). Sparkup Business, Bridging the Generation Gap in the Workplace; https://www.bworldonline.com/sparkup-spark-on-gen-zers-and-bridging-generation-gap-in-theworkplace/

Johari, R. J., Mohd-Sanusi, Z., \& Chong, V. K. (2017). Effects of Auditors' Ethical Orientation and SelfInterest Independence Threat on the Mediating Role of Moral Intensity and Ethical Decision-Making Process. International Journal of Auditing, 21(1), 38-58. ; https://doi.org/10.1111/ijau.12080

Kagan, Julia (2019). Generation X. https://www.investopedia.com/terms/g/generation-Xgenx.asp

Karacaer, S. ; Gohar, R. ; Aygün, M. \& Sayin, C. (2009). Effects of personal values on auditor's ethical decisions: A comparison of pakistani and turkish professional auditors. _Journal of Business Ethics_ 88 (1):53 - 64 .

Ki, E. J., Lee, J., \& Choi, H. L. (2012). Factors affecting ethical practice of public relations professionals within public relations firms. Asian Journal of Business Ethics, 12), 123-141. Retrieved from: https://doi.org/10.1007/s13520-011-0013-1

Knafo-Noam, A. \& Sagiv, L. (2004). Values and work environment: Mapping 32 occupations. European Journal of Psychology of Education. 19. 255-273. 10.1007/BF03173223.

Kock, N. and Hadaya, P. (2018), "Minimum sample size estimation in PLS-SEM: the inverse square root and gamma-exponential methods", Information Systems Journal, Vol. 28 No.1， pp. ～227-261, available at: http://doi.org/10.1111/isj.12131 
Journal of Governance Risk Management Compliance and Sustainability (JGRCS), Vol. 1 (1), 26-49 Moderated Mediation of Ethical Considerations between Individual Values and Values in the Practice of the CPA Profession

Arnold V. Salcedo

Lamm, E., \& Meeks, M. D. (2009). Workplace fun: The moderating effects of generational differences. Employee relations, 31(6), 613-631. Retrieved from: https://www.emeraldinsight.com/doi/abs/10.1108/01425450910991767

Lieber, L.D. (2010). How HR Can Assist in Managing the Four Generations in Today's

Workplace. Employment Relations Today, 36(4), 85-91.

Lozano, J. M. (2003). An Approach to Organizational Ethics. (pages 46-47). http://proxymy.esade.edu/gd/facultybio/publicos_ethics_2003.pdf

Lu, A. C. C., \& Gursoy, D. (2016). Impact of job burnout on satisfaction and turnover intention: Do generational differences matter?. Journal of Hospitality \& Tourism Research, 40(2), 210-235

Mac Donald, C. (2011). The Business Ethics Blog: Ethics, Definition. https://businessethicsblog.com/2010/03/21/ethics-definition/

Mendoza, R. (2012) Accountancy Research Domdae Publishing Copyright 2012.

Merriam-Webster: Definition of Ethical Consideration. https://www.merriamwebster.com/legal/ethical\%20consideration

Naidoo, M., 2014, 'The potential of spiritual leadership in workplace spirituality', Koers - Bulletin for Christian Scholarship 79(2), 1-8. http://dx.doi.org/10.4102/ koersv79i22 124

Nasrabadi, A \& Arbabian, A. (2015). The effects of professional ethics and commitment on audit quality.Management Science Letters , 5(11), 1023-1028.

Necla, S. F. (2016). Pre-Service Teachers' Personal Value Orientations and Attitudes toward the Teaching Profession in Turkey. Educational Research and Reviews, 11(20), 1944-1955. Retrieved from: https://files.eric.ed.gov/fulltext/EJ1118133.pdf

Nwanyanwu, L. (2018). Accountants' ethics and fraud control in Nigeria: The emergence of a fraud control

model https://www.researchgate.net/publication/322294053_Accountants'_ethics_and_fraud_control_in_Nige ria_The_emergence_of_a_fraud_control_model

Pappas, C. (2016). 8 Important Characteristics Of Baby Boomers eLearning Professionals Should Know. https://www.thesun.co.uk/fabulous/5505402/millennials-baby-boomers-generation-groups-z$\mathrm{y}$-x-explained/

Philippine Institute of Certified Public Accountants Angeles City Chapter (2017). List of Registered Members for Federation Year 2017-2018.

Popoola, I. T., Garner, B., Ammeter, A., Krey, N., Beu Ammeter, D., \& Schafer, S. (2017). How does ethics institutionalization reduce academic cheating?. Journal of Education for Business, 92(1), 29-35. https://doi.org/10.1080/08832323.2016.1274710

Professional Regulatory Board of Accountancy (2019). Revised Code of Ethics for Professional Accountants as the "Code of Ethics for Professional Accountants in the Philippines", and Prescribing Amendments Therefor. https://boa.com.ph/about-the-boa/code-of-ethics/

Proence, E. Jose (2004). Ethics Orientation as a Mediator of Organizational Integrity in Health Services Organizations. Health Care Management Review. Retrieved from: https://journals.lww.com/hcmrjournal/Abstract/2004/01000/Ethics_Orientation_as_a_Mediator_of_Or ganizational.6.aspx

Rodriguez-Valdes, L. (2015). Generation Gap in the Workplace. Philippine Institute of Certified Public Accountants http://www.picpa.com.ph/attachment/6282016105639789.pdf

Schreuder, A.M.G. \& Coetzee, M., (2011). Careers: An organisational perspective, 4th edn., Juta, Cape Town. 
Schwartz S.H. (2012). An Overview of Schwartz THeory of Basic Values. Online Readings of Psychology and Culture 2(1). https: //doi.org/10.9707//2307-0919.1116

Shafer, W. E. Morris, R. and Ketchand, E. Alice A.(2001) "Effects of personal values on auditors' ethical decisions", Accounting, Auditing \& Accountability Journal, Vol. 14 Issue: 3, pp.254-277, https://doi.org/10.1108/EUM0000000005517

Simón, J., Pérez-Testor, C., Kurz, E. A., Danioni, F., Iriarte, L., Cormenzana, S., \& Martínez, A. (2017). The Portrait Values Questionnaire: A bibliographic and bibliometric review of the instrument. Aloma: revista de psicologia, ciències de l'educació i de l'esport Blanquerna, 35(1), 39-50. https://www.raco.cat/index.php/Aloma/article/view/324083

Steenhaut, S., \& Van Kenhove, P. (2006). An empirical investigation of the relationships among a consumer's personal values, ethical ideology and ethical beliefs. Journal of Business Ethics, 64(2), 137-155. Retrieved from: https://link.springer.com/article/10.1007/s10551-005-5905-3

Tal, C. (2014). "Self-Transcendence Values, Relationships, and Participatory Practice in Early Childhood Education," Education Research International, vol. 2014, Article ID 371831, 8 pages, 2014. Retrieved from: https://doi.org/10.1155/2014/371831.

Thompshon, C. (2018). The Case for Six Point Likert Scale. https://www.quantumworkplace.com/future-of-work/the-case-for-the-six-point-likert-scale

Time Magazine (2013). The Millenial Generation. https://time.com/247/millennials-the-me-meme-generation/

Vehovar A. \& Mumel D. \& Hauptman L. (2018). "A Conceptual Model of the Relationship between Personal Values and Personal Tax Culture Regarding the Perception of Tax System Fairness," Naše gospodarstvo/Our economy, Sciendo, vol. 64(1), pages 41-47, March.

Venezia, G., Venezia, C. C., \& Hung, C. W. (2010). A comparative study of ethical work climates among public and private sector Asian accountants. International Business and Economics Research Journal, 9(4), 77-86. Retrieved from:http://clutejournals.com/index.php/IBER/article/view/555

Waldron, M., \& Fisher, R. T. (2016). Values and Ethical Judgments: A Study of the Adequacy of Students as Surrogates for Practicing Accountants. Retrieved from: https://ir.canterbury.ac.nz/.../12663668_Meditari\%20Conference

Weedmark, David (2018). Work, careers and jobs. What are the Values in the Workplace? https://work.chron.com/values-workplace-29708.html

Wilson, B., Squires, M., Widger, K., Cranley, L. and Tourange, A. (2008). Job satisfaction among multigenerational nursing workforce. Journal of Nursing Management, 16, 716-723

Yang, H. L. \& Wu, W. P. (2009) The effect of moral intensity on ethical decision making in accounting, Journal of Moral Education, 38:3, 335-351, DOI: 10.1080/03057240903101606

Yates, M. (2018). Leader Values Limited - Values and Ethics Determines One Character: https://www.leader-values.com/article.php?aid=576

Young, M.A. The effects of Values, Conscientousness, and Self-efficacy on Ethical Decision Making https://digitalcommons.unomaha.edu/cgi/viewcontent.cgi?article=1322\&context=studentwork

Zabel, K. L., Biermeier-Hanson, B. B., Baltes, B. B., Early, B. J., \& Shepard, A. (2017). Generational differences in work ethic: Fact or fiction? Journal of Business and Psychology, 32(3), 301-315. Retrieved from: https://link.springer.com/article/10.1007/s10869-016-9466-5 